\title{
O gênero textual reportagem impressa em sala de aula: uma proposta de trabalho a partir da elaboração de Modelo Didático de Gênero e de Sequência Didática ${ }^{1}$
}

\author{
Rosangela Oro Brocardo* \\ Terezinha da Conceição Costa-Hubes**
}

\begin{abstract}
Resumo
Tendo em vista a perspectiva de que os gêneros textuais podem ser tomados como instrumento para mediar o processo ensino-aprendizagem da língua e das marcas discursivas que a constituem, torna-se importante encontrar caminhos para ensiná-los. Nesse sentido, propomos um trabalho pautado na proposta de trabalho da Sequência Didática (SD), conforme Dolz, Noverraz e Schneuwly (2004) e adaptação de Costa-Hübes (2008), constituído a partir da elaboração de Modelo Didático do Gênero (MDG), segundo as orientações de Schneuwly e Dolz (2004) e Machado e Cristóvão (2006). O objetivo reside na tentativa de aclarar os propósitos do trabalho com o gênero na sala de aula, ampliando o conhecimento sobre sua função social, seu contexto de produção, sua organização composicional e suas marcas linguísticas.
\end{abstract}

Palavras-chave: Gênero Textual; Sequência Didática; Modelo Didático de Gênero; Reportagem Impressa.

\section{The printed report genre in the classroom: a working proposal from the development of a Didactic Model} Gender and Didactic Sequence

\begin{abstract}
Given the prospect that textual genres can be taken as a tool to mediate the teaching-learning process of the language and discursive marks that constitute them, it becomes important to find ways to teach them. In this direction, we suggest a study based on the Didactic Sequence (DS) work proposal, as proposed by Dolz, Noverraz and Schneuwly (2004) and adaptation of Costa-Hübes (2008), constituted from the development of a Didactic Model of Genre (DMG), according to the guidelines of Schneuwly and Dolz (2004) and Machado and Cristóvão (2006). The objective consists in the attempt to clarify the purposes of the work with the genre in the classroom, expanding the knowledge about its social role, its context of production, its compositional organization and its linguistic marks.

Keywords: Textual Genre; Didactic Sequence, Didactic Model of Genre; Printed Report.
\end{abstract}

\section{Introdução}

Neste artigo, pretendemos apresentar uma experiência de elaboração de Modelo Didático de Gênero com o gênero reportagem impressa, e, a partir de pressupostos teóricos, relacionar com o ensino. Para isso, apresentaremos, como embasamento teórico, os estudos de Dolz e Schneuwly (2004) e Machado e Cristovão (2006), no que se refere à elaboração do Modelo Didático de Gênero (a partir de agora, MDG), e também resultados da aplicação de uma Sequência Didática (SD), a partir do gênero Reportagem Impressa, em uma turma de alunos do $4^{\circ}$ ano Técnico em Administração do Ensino Médio.

Esta proposta de trabalho com os gêneros textuais parte da ideia de que a língua é social e, portanto, revela-se em textos (orais e escritos) que circulam na sociedade, cumprindo uma função específica: fazer rir, fazer chorar, informar, orientar, persuadir etc. Assim, os textos podem ser

* Endereço eletrônico: rosangela.oro@gmail.com

** Endereço eletrônico: tehubes@gmail.com compreendidos como a materialidade do discurso de determinada esfera de atividade humana que, para fazer-se presente socialmente, elabora seus enunciados de maneira "relativamente estável" (BAKHTIN, 2003, p. 283), denominado por esse mesmo autor como gênero do discurso.

A ação da linguagem e sua função como mediadora das práticas sociais, no que se refere à análise da produção, compreensão, interpretação de enunciados orais e escritos, torna-se, assim, objeto de estudo relevante. Nesse sentido, Bronckart afirma que:

Toda ação da linguagem implica diversas capacidades do sujeito: adaptar-se às características do contexto e do referente, mobilizar modelos discursivos (capacidades discursivas), dominar as operações psicolinguísticas e as unidades linguísticas (capacidades linguístico-discursivas) (BRONCKART, 2003, p. 74). 
Reconhecendo, portanto, esse caráter social da linguagem, diversos documentos como os Parâmetros Curriculares Nacionais - PCN (BRASIL, 1998) e as Diretrizes Curriculares de Língua Portuguesa do Estado do Paraná - DCE (PARANÁ, 2008), por exemplo, tentam abordar a questão. Porém, observamos que, mesmo com uma fundamentação teórica consistente, faltam orientações didático-metodológicas de como efetivamente relacionar tais discussões com a prática escolar. E essa lacuna tem gerado certos desvios quanto ao lugar que os gêneros deveriam ocupar no contexto escolar, sendo adotados, em muitas situações, como pretexto para o ensino da gramática, desprovidos de qualquer relação com uma situação de comunicação autêntica.

Nesse sentido, o desenvolvimento do MDG mostra-se como fundamental, tanto no sentido de se constituir como uma orientação para as intervenções dos professores, quanto ao fato de delimitar as dimensões ensináveis, a partir das quais as SD podem ser produzidas e aplicadas.

A fim de aclarar essas questões e de encontrar caminhos para o trabalho com os gêneros na sala de aula, a reportagem impressa foi selecionada, visando reflexões sobre sua função social, seu contexto de produção, sua organização composicional, lançando um olhar, também, para suas marcas linguísticas, por meio da construção de um MDG, imprescindível para que a SD seja adequadamente constituída.

\section{Concepção de gênero e suas perspectivas de encaminhamento em sala de aula}

No Brasil, somente a partir dos anos 2000 tem sido dada maior atenção às teorias de gênero (de textos/do discurso). Pelo menos em parte, isso se deve à abordagem que os PCN (BRASIL,1998) fizeram sobre o assunto, ao colocar a questão dos gêneros no centro das discussões. Trata-se, então, de enfocar, em sala de aula, o trabalho com textos de diferentes gêneros, provocando reflexões sobre seu contexto de produção, evidenciando seus aspectos discursivos, assim como suas propriedades formais, valorizando o estudo da situação de produção, do contexto e da circulação dos textos.

Todavia, para que essa proposta se torne compreensível, é necessário, antes de mais nada, que compreendamos o que são gêneros textuais. Para isso, uma grande contribuição vem de Bakhtin , ao destacar o caráter mediador e social do uso que fazemos da linguagem. Todos os usuários de uma língua organizam sua fala em função do gênero selecionado para a situação de interação, mesmo que de maneira empírica. Assim, todo gênero se realiza em textos, sejam eles orais ou escritos. Para Bakhtin, os tipos relativamente estáveis de enunciados são chamados de gêneros discursivos, o que compreende certa mobilidade, dinamismo com relação às formas de materialização da língua. Nesse sentido, o autor afirma:

O enunciado reflete as condições específicas e as finalidades de cada uma das esferas, não só por seu conteúdo (temático) e por seu estilo verbal, ou seja, para seleção operada nos recursos da língua - recursos lexicais, fraseológicos e gramaticais, mas também, e sobretudo, por sua construção composicional. Estes três elementos (conteúdo temático, estilo e construção composicional) fundem-se indissoluvelmente no todo do enunciado $e$ todos eles são marcados pela especificidade de uma esfera de comunicação (BAKHTIN, 2003, p. 279).

Assim considerados, os gêneros devem ser compreendidos como os discursos que proferimos em nossas situações de interação, organizados por enunciados que, embora constituídos individualmente, revelam a esfera social que representam ao materializarem-se em textos (orais ou escritos). Schneuwly e Dolz resumem a posição de Bakhtin, ao retomar os elementos a ser considerados na identificação dos gêneros:

- Cada esfera de troca social elabora tipos relativamente estáveis de enunciados: os gêneros;

- Três elementos os caracterizam: conteúdo temático, estilo, construção composicional; - A escolha de um gênero se determina pela esfera, as necessidades da temática, o conjunto dos participantes e a vontade enunciativa ou intenção do locutor (SCHNEUWLY e DOLZ, 2004, p. 25).

$\mathrm{Na}$ escola, em relação ao trabalho com o texto, sugere-se ter os gêneros como referência, adotando-os como instrumentos da Língua Portuguesa, de modo que contribua para o aprimoramento linguístico, ao transitar por diversas esferas de comunicação, por meio de práticas que contemplem tanto a escrita, quanto a oralidade e a 
leitura. Como afirma Bakhtin:

Quanto melhor dominamos os gêneros tanto mais livremente os empregamos, tanto mais plena e nitidamente descobrimos neles a nossa individualidade, refletimos de modo mais flexível e sutil a situação singular da comunicação; em suma, realizamos de modo mais acabado o nosso livre projeto de discurso (BAKHTIN, 2003, p.285).

Nessa perspectiva, para Marcuschi (2006) os gêneros são enunciados no plano das ações sociais situadas e históricas. Por isso, a competência discursiva de um falante está associada à sua capacidade de interagir com as formações sóciodiscursivas existentes no mundo. Essa interação, segundo Bronckart (2003), se dá por meio de textos empíricos.

O texto singular ou empírico designa uma unidade concreta de produção de linguagem, que pertence a um gênero, composta por vários tipos de discurso, e que também apresenta os traços das decisões tomadas pelo produtor individual em função da sua situação de comunicação particular (BRONCKART, 2003, p.108).

Ao assumirmos essas bases teóricas, assumimos uma concepção dialógica de linguagem, o que irá refletir, de certa forma, nos encaminhamentos didáticos do ensino da língua. Ensiná-la, sob essa perspectiva, significa propiciar aos alunos, situações reais de uso da língua na produção de textos de diferentes gêneros.

Para isso, tendo como pressupostos as dificuldades encontradas pelos professores no que tange ao ensino da expressão oral/escrita, sugere-se que a linguagem seja trabalhada sob a perspectiva sociointeracionista, nos termos vygostkyanos e bakhtinianos, constituindo-se, como a base do trabalho, os gêneros discursivos e, mais especificamente, a reportagem jornalística impressa.

\section{Metodologia de análise: Modelo Didático de Gênero como pressuposto para a construção de Sequências Didáticas}

Para o trabalho com um gênero na sala de aula, é importante, antes de tudo, que o professor reconheça-o quanto à sua função social, ao seu contexto de produção, à sua estrutura organizacional e às suas marcas linguísticas e textuais.

A construção do MDG Reportagem Impressa colabora nesse sentido, fazendo apontamentos quanto às características predominantes do gênero a ser trabalhado. Para isso, avalia a forma como este se constitui, apresenta seu contexto de uso e sua esfera de circulação, bem como suas marcas linguísticas, o que contribui para o seu deslocamento para uma situação didática, já que fornece dados importantes que poderão ser trabalhados na elaboração de SD.

Para Cristóvão, que adota a concepção de MDG segundo Dolz e Schneuwly (2004), a análise e a classificação dos textos, bem como a identificação dos gêneros são necessárias para a construção de um MDG que apontará os elementos ensináveis num processo de ensino/aprendizagem. Nessa perspectiva, segundo a autora, o modelo didático é criado a partir de:

a) resultados de aprendizagem expressos por documentos oficiais e da determinação das capacidades reveladas pelos alunos;

b) conhecimento dos experts daquele gênero e conhecimentos linguísticos do gênero;

c) capacidade de linguagem dos alunos. (...) O modelo didático visa apontar, segundo o que é ensinável, às capacidades de linguagem que poderão ser desenvolvidas a partir do trabalho com os textos pertencentes a gêneros específicos que circulam em nosso meio (CRISTÓVÃO, 2002, p. 43-44).

Assim, faz-se de suma importância, se não a consulta a MDG já disponíveis, a elaboração prévia destes, nos moldes propostos por Schneuwly e Dolz (2004), a fim de orientar um encaminhamento adequado na elaboração de SD, permitindo, com isso, uma progressão no que se refere ao trabalho com as marcas do gênero.

Segundo estes autores,

(...) Um modelo didático apresenta, então, em resumo, duas grandes características:

1. Ele se constitui uma síntese com objetivo prático, destinada a orientar as intervenções dos professores;

2. Ele evidencia as dimensões ensináveis, com base nas quais diversas sequências didáticas podem ser concebidas 
(SCHNEUWLY e DOLZ, 2004, p. 82).

Ao revelar as marcas predominantes do gênero, já indica, também, quais os elementos mais importantes e que devem ser enfocados ao trabalhálo. A partir dessas orientações, o professor terá mais segurança para fazer as intervenções necessárias em momentos de ensino/aprendizagem.

Ainda sobre o MDG, segundo Machado e Cristóvão (2006), no mínimo, os seguintes elementos devem ser considerados:

a) as características da situação de produção (quem é o emissor, em que papel social se encontra, a quem se dirige, em que papel se encontra o receptor, em que local é produzido, em qual instituição social se produz e circula, em que momento, em qual suporte, com qual objetivo, em que tipo de linguagem, qual é a atividade não verbal a que se relaciona, qual o valor social que lhe é atribuído etc.);

b) os conteúdos típicos do gênero;

c) as diferentes formas de mobilizar esses conteúdos;

d) a construção composicional característica do gênero, ou seja, o plano global mais comum que organiza seus conteúdos;

e) o seu estilo particular. (MACHADO e CRISTOVÃO, 2006, p. 11-12).

Conforme exposição das autoras, são pelo menos cinco os elementos que podem/devem ser estudados/pesquisados em um gênero: a situação de produção, o conteúdo temático, a(s) forma(s) de abordar o tema, a estrutura composicional e as marcas linguísticas. No entanto, tais elementos devem ser analisados no conjunto, na representação do todo, que é o gênero. Se uma dessas marcas for privilegiada em detrimento de outra(s), perde-se a organicidade do gênero. Isso significa dizer que trabalhá-lo na sala de aula pressupõe uma abordagem conjunta entre leitura, oralidade e escrita, entendendo-as como eixos estruturantes para se chegar ao reconhecimento da função social e do contexto de produção, assim como de marcas linguísticas e textuais, do gênero selecionado, de forma orgânica articulada.

Quanto ao procedimento metodológico da SD, Dolz, Noverraz e Schneuwly o definem como "um conjunto de atividades escolares organizadas de maneira sistemática, em torno de um gênero textual oral ou escrito" (DOLZ, NOVERRAZ e SCHNEUWLY, 2004, p.97), cuja finalidade é trabalhar com gêneros não dominados ou dominados parcialmente pelo aluno.

Inicia-se, normalmente, pela apresentação da situação, detalhando a situação de interlocução que será realizada por meio do gênero selecionado. Em seguida, parte-se para a produção de um texto inicial, o qual servirá de referência para o professor identificar os encaminhamentos que deverá seguir. Tendo em vista o levantamento das principais dificuldades a partir dos textos dos alunos, elaborase módulos de atividades diversificadas, os quais contemplarão os diversos elementos constituintes do gênero abordado e que ainda não foram sistematizados pelos alunos. A SD é finalizada com outra produção, quando o aluno poderá incorporar os conhecimentos adquiridos nos módulos. A figura 1, abaixo, resume tal encaminhamento:

Figura 01: esquema da Sequência Didática

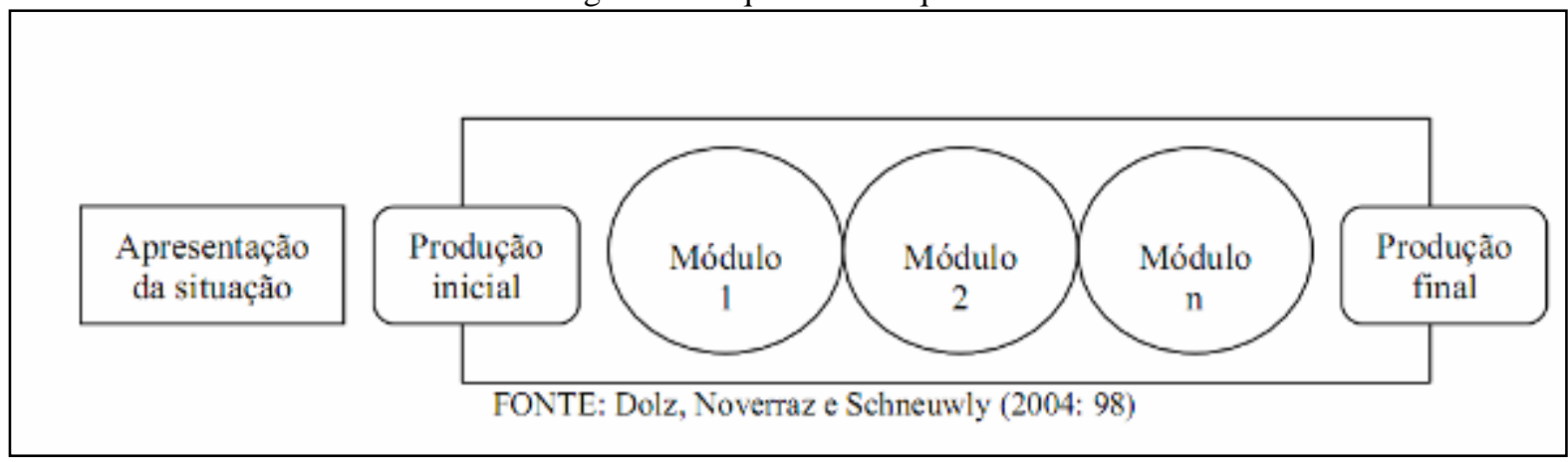

Esse encaminhamento, após a apresentação da situação, remete-nos à necessidade de propor aos alunos uma situação concreta de uso da língua, para a qual são instigados a interagir efetivamente por meio da linguagem, selecionando, dessa forma, estratégias, de acordo com sua intencionalidade. Para melhor organizar as SD e selecionar adequadamente os gêneros com os quais se pretende 


\section{Modelo Didático de Gênero e de Sequência Didática}

trabalhar, os autores afirmam que os gêneros podem ser agrupados em função de regularidades linguísticas e de transferências possíveis, segundo capacidades de linguagem dominantes.

Porém, antes da produção inicial de um texto do gênero selecionado, sentimos a necessidade de propiciar, aos alunos, situações de reconhecimento do gênero, oportunizadas por atividades de pesquisa, leitura e análise linguística de textos prontos, já publicados, que circulam socialmente. Por isso, optamos pela adaptação metodológica da SD, apresentada por Costa-Hübes (apud AMOP, 2007) e Costa-Hübes (2008). Na verdade, trata-se da inserção do módulo reconhecimento do gênero antes da produção inicial, conforme explicitado abaixo na figura 2 :

Figura 02: Esquema da Sequência Didática adaptada

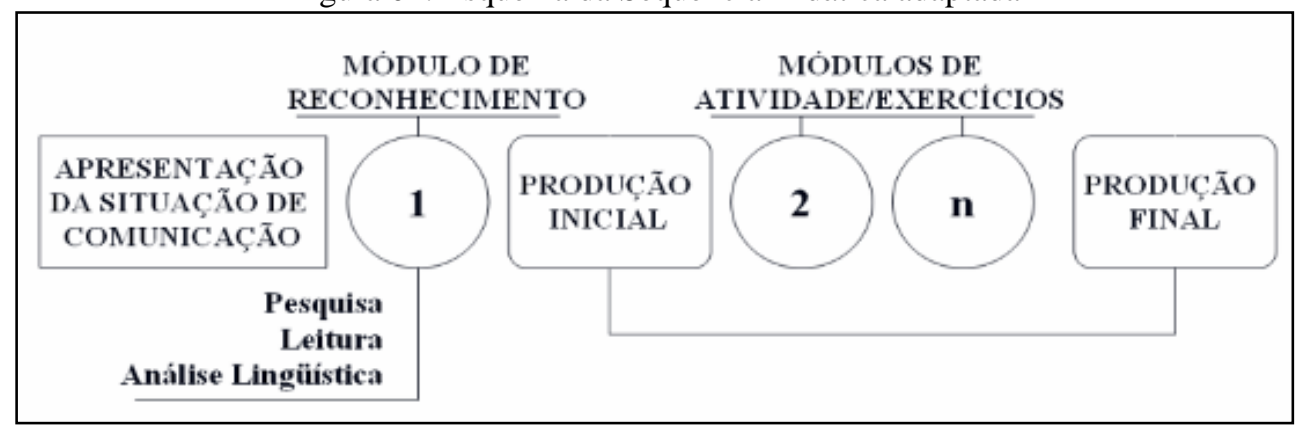

Propiciar situações de pesquisa, leitura e análise linguística antes da produção inicial, significa subsidiar os alunos com conhecimentos necessários para que o processo da produção (oral ou escrita) aconteça. Analisando bons textos, refletindo sobre seu contexto de produção e sua forma de organização, o aluno estará melhor preparado para produzir o seu texto.

Outro elemento importante desse módulo de reconhecimento, refere-se ao incentivo à pesquisa. Ao valorizar tal ação, o professor entende que as informações sobre o gênero não devem ser repassadas gratuitamente, prontas, acabadas. Ao contrário, deve ser incentivada a pesquisa de vários textos do gênero, a fim de que o aluno perceba-o como um instrumento relativamente estável.

Adotando a base teórica dos gêneros, somando-se a ela metodologia da SD conforme adaptação de Costa-Hübes (apud AMOP, 2007) e Costa-Hübes (2008), planejamos uma SD com o gênero Reportagem Impressa, tendo como base o MDG. Para melhor explicitarmos essa tentativa de transposição didática, detalharemos, em seguida, o percurso da análise.

\section{Descrição do corpus da pesquisa e dos procedimentos de análise}

Foram selecionadas, para a construção do MDG Reportagem Impressa, 10 reportagens de diferentes revistas, as quais apresentavam públicoalvo bastante diverso. Quanto à constituição propriamente dita do MDG e os critérios selecionados para análise, temos em vista que toda produção linguística é uma ação social situada, utilizada por indivíduos em formações sociais específicas, conforme pressupostos teóricos propostos por Bakhtin (1999; 2003), Bronckart (2003), e, posteriormente, analisado por Marcuschi (2007; 2008) e Baltar (2004).

Nesse sentido, no MDG, em primeiro plano, buscamos analisar a situação de ação da linguagem, as propriedades dos mundos formais (físico, social e subjetivo) que norteiam a produção do gênero reportagem. Em seguida, avaliamos também a infraestrutura geral de um texto, tendo em vista que, diante de um quadro contextual, o locutor seleciona estratégias diferenciadas de acordo com a situação de linguagem na qual está inserido, com o conteúdo que deseja abordar, com os parâmetros dos mundos físico e sócio-subjetivo. Definimos, dessa forma, o gênero determinado, articulando os tipos de discursos, organizados através de sequências textuais. Bronckart (2003) chama isso de folhado textual, "aspectos que tramam a organização dos textos" (BALTAR, 2004, p. 72).

Num terceiro momento, procedemos à análise de recursos linguísticos, tais como: modalizadores, dêiticos, utilização de elementos coesivos, tanto referenciais, quanto sequenciais, escolha de tempos verbais, lexicais, dentre outros itens que estabelecem relações com a intencionalidade do locutor e a constituição do gênero, sua circulação.

$\mathrm{Na}$ tentativa de garantir maior compreensão sobre a análise efetuada no MDG, a seguir, 
transcrevemos aspectos observados no gênero Reportagem Impressa.

\subsection{Contextos físico e sócio-subjetivo de produção}

Observamos, na análise abordada nos textos que o elemento mais importante, determinando outros aspectos constitutivos do gênero, diz respeito ao momento de produção (o contexto histórico imediato) das reportagens. Os locutores, normalmente repórteres das revistas (veículo/suporte do gênero em questão), buscam selecionar temáticas relacionadas a fatos da atualidade, ou assuntos gerais, atemporais, mas de interesse constante por parte do público-alvo (interlocutores).

Por meio da análise comparativa de reportagens de diferentes revistas, constatamos que, de acordo com o público-alvo, o locutor seleciona estratégias, mecanismos linguísticos diferenciados. Isso se mostra na escolha lexical, nos níveis de linguagem, na consideração da posição social do interlocutor, buscando contemplar suas expectativas, denunciando intencionalidades.Tanto o lugar, quanto o momento de interação aos quais as reportagens remetem, representam fatores determinantes de seu conteúdo, dos argumentos utilizados pelo locutor, tendo em vista os efeitos que deseja produzir sobre seu interlocutor.

Com relação ao contexto físico, ainda, cabenos ressaltar o papel do veículo/suporte e sua influência sobre a constituição do gênero. Nesse sentido, observamos, nas reportagens analisadas, que estas não se mostram indiferentes ao veículo/suporte em que circulam, definindo, de certa forma, o formato do gênero, ao privilegiar estratégias, preferências estilísticas utilizadas na constituição do texto.

\subsubsection{A esfera jornalística e o gênero reportagem impressa}

O objeto de estudo dessa pesquisa, a reportagem jornalística impressa, necessita de maiores esclarecimentos sobre muitas questões. Por exemplo: qual é, afinal, a função social desse gênero que o caracteriza como tal? Quais são seus veículos/suportes de circulação, atualmente? Quais as suas formas de apresentação nestes veículos/suportes? Há marcas de polifonia? Como elas se desenvolvem? Pode-se afirmar tratar-se de um gênero híbrido? Nesse caso, quais são as variantes do gênero? Quais marcas linguísticas lhe são próprias? Como representa a esfera jornalística e o mundo discursivo ao qual pertence?

De início, podemos constatar que este gênero representa uma atividade textual de grande importância na esfera jornalística, uma vez que objetiva a divulgação de um fato, porém de maneira mais aprofundada, apresentando elementos de comprovação, descrição detalhada e, em muitos textos, destacam-se até recursos de argumentação. Pode-se afirmar, portanto, que se configura como uma notícia ampliada. Sua circulação se dá, normalmente, em diversos veículos/suportes, o que influencia, de certa forma, em sua constituição, tanto formal, quanto linguística. Por exemplo, reportagens veiculadas em jornal online, se comparadas com outras veiculadas em uma revista semanal impressa, assumem formatos diferenciados, determinados por diversos fatores, que vão desde o próprio suporte, até a influência decisiva do público alvo ao qual se destinam. Porém, um ponto em comum, há que se ressaltar: seu objetivo principal está no aprofundamento dos fatos.

Para Baltar,

A reportagem é o gênero mais complexo e mais elaborado do jornalismo. Envolve coleta minuciosa de dados, entrevistas, consulta a outras mídias como rádio, TV e internet. Predominam os tipos de discurso do mundo do narrar: narração e o relato interativo, com seqüencias narrativas, descritivas e dialogais (BALTAR, 2004, p. 132).

Observamos, ainda, que, em muitas situações, o gênero reportagem assume caráter híbrido, já que sua composição absorve ou utiliza-se de vários outros gêneros, como a entrevista, o gráfico, a charge, a fotografia, etc. Marcuschi, nesse sentido afirma:

É bastante comum nos órgãos de imprensa que se usem as contaminações de gêneros ou se proceda à hibridização como forma de chamar mais a atenção e motivar a leitura. De algum modo, parece que essa estratégia tem o poder quase mágico de levar as pessoas a interpretarem muito mais e com mais intensidade o que ali está (MARCUSCHI, 2008, p. 168).

Para melhor compreendê-lo, torna-se 
fundamental o estudo de como o gênero se situa, se caracteriza e qual sua relação com a esfera discursiva a que pertence, o que pode ser feito a partir da construção de Modelo Didático de Gênero (MDG), conforme explicitamos a seguir.

\subsection{Plano Discursivo}

\subsubsection{Definição e Estrutura da reportagem}

Sendo a reportagem um gênero textual da esfera jornalística, o objetivo básico se constitui no propósito de trazer informações atualizadas e detalhadas sobre fatos, acontecimentos, temas ou sobre personalidades de interesse do público-alvo do veículo de comunicação, no caso, da revista. Porém, observamos que este gênero objetiva, implicitamente, formar a opinião dos interlocutores a respeito de determinado assunto, o que foi possível determinar na análise da utilização de modalizadores por parte do locutor.

As reportagens, quanto à sua estrutura, de um modo geral, podem conter os seguintes componentes:

Quadro 02: estrutura composicional do gênero textual reportagem impressa

1-Títulos: há implícita uma função apelativa com a finalidade de chamar a atenção do leitor.

2-Subtítulos (ou gravatas): são as linhas colocadas abaixo do título que têm a função de completar o título e de apresentar, de maneira resumida, o assunto.

3-Olho: recurso gráfico no qual é retida uma frase de efeito ou impactante e é colocada em destaque, entre aspas, dentro de um pequeno boxe ou espaço e em meio às colunas em que são escritas as reportagens.

4-Lead: relato inicial do texto, devendo informar o que é mais importante e não o mais interessante.

5-Boxes: caixa de texto diferenciada pela cor e que ganha destaque por utilizar textos combinados com tabelas, gráficos ou fotos referenciando-se ao assunto (combinação entre linguagem verbal e não-verbal ou referência a outros textos de diferentes gêneros textuais). reportagem:

É o gênero mais complexo e mais elaborado do jornalismo. (...) Predominam os tipos de discurso do mundo do narrar: narração e o relato interativo, com sequências narrativas, descritivas e dialogais. (...)
Envolve coleta minuciosa de dados, entrevistas, consultas a outras mídias como rádio, tevê e internet (BALTAR, 2004, p.132).

A fim de exemplificar de que forma este gênero normalmente se constitui, citamos a reportagem abaixo:

Figura 3: exemplo de constituição de uma reportagem impressa

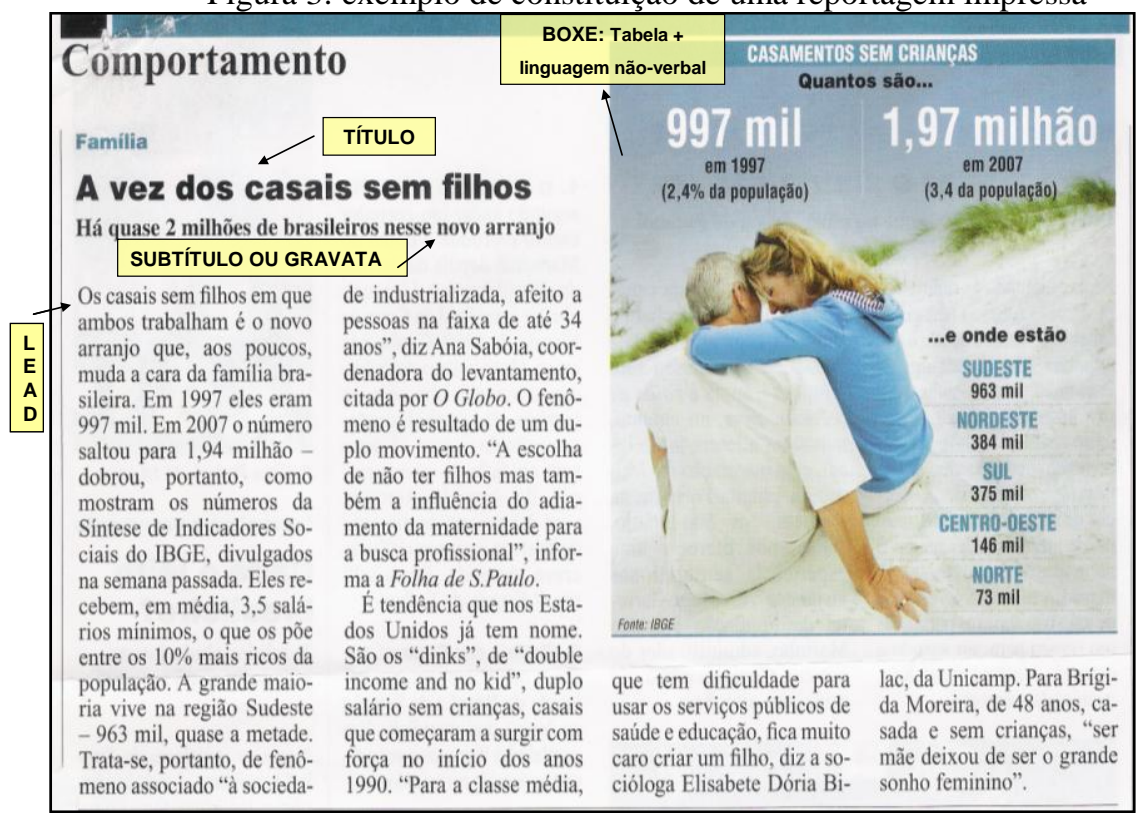

Fonte: Revista da Semana, 02/10/08, reportagem: A vez dos casais sem filhos. 
Notamos, no caso da reportagem acima, que em seu suporte, ao observar que seu público-alvo demonstra preferência por textos mais concisos, apresentam reportagens com tal característica.
$\mathrm{Na}$ esquematização seguinte, procuramos explicitar melhor algumas das relações gerais que se estabelecem na constituição do gênero textual referido, tomando essa reportagem como base:

Figura 4: referências gerais aos elementos que constituem a reportagem anterior

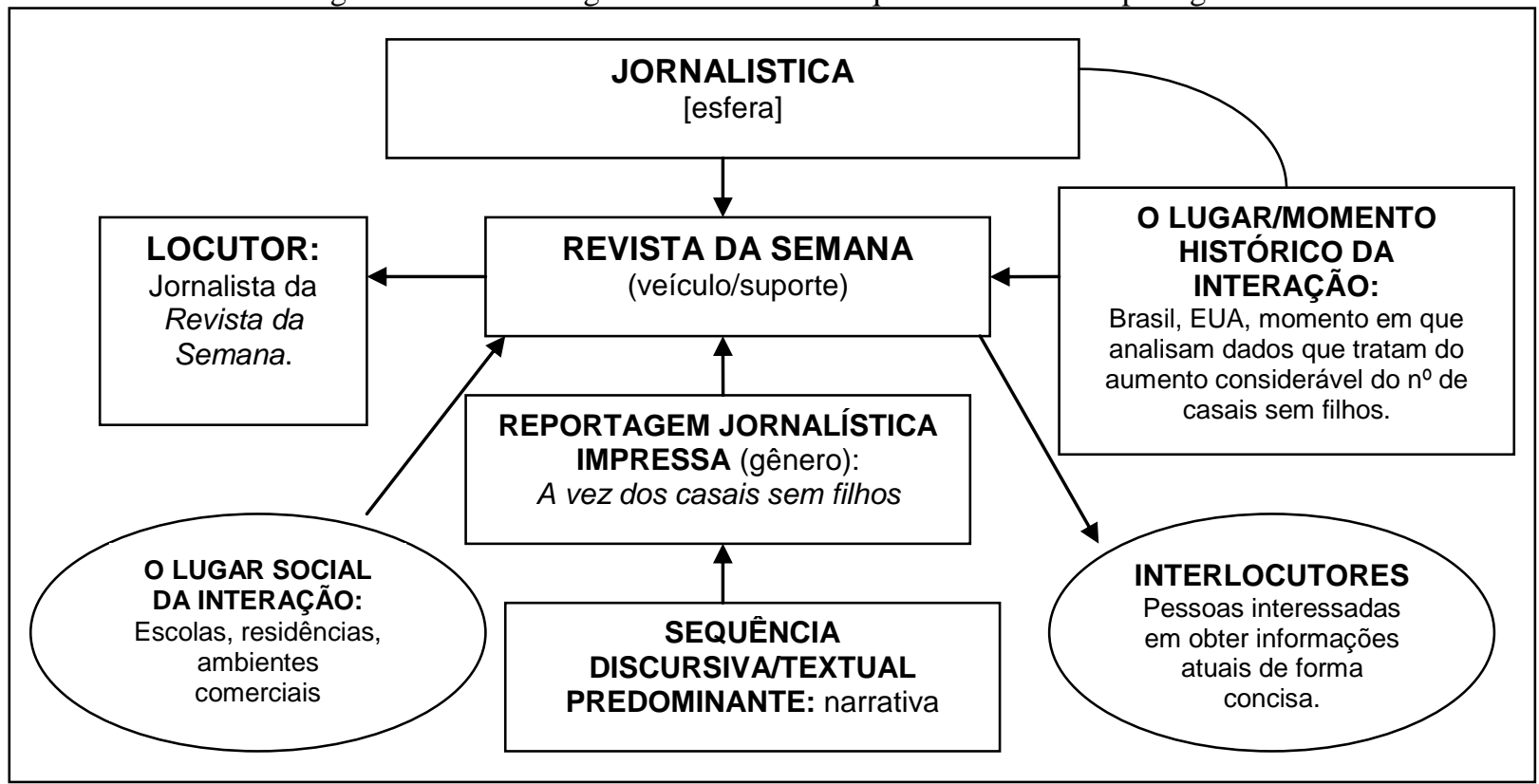

No exposto acima, merece maior reflexão as influências mútuas entre os gêneros e seus veículos/suportes. $\mathrm{O}$ que se revela é que os gêneros não são indiferentes nos diversos veículos/suportes possíveis, nem imunes a eles, assim como a percepção das influências do momento histórico e da relação entre locutor/interlocutor, imprescindíveis para uma melhor compreensão do sentido global do texto.

Na construção do MDG da Reportagem impressa, observamos, também, que na grande maioria dos textos analisados, há predominância da sequência narrativa (conforme exemplificado na reportagem acima), porém, a presença de outros tipos de sequências é recorrente. Nesse sentido, Baltar concorda que "(...) há uma maioria de textos heterogêneos, compostos por mais de um tipo de discurso/modalidade discursiva, em que um tipo está em relação de predomínio e outro, ou outros tipos, em relação de subordinação" (BALTAR, 2004, p.72). É o caso desse gênero que, em geral, apresenta diferentes sequências discursivas/textuais em sua constituição, a saber: narrativa, descritiva, argumentativa e expositiva. No entanto, como observamos no MDG, há a predominância da narrativa, aliada, em segundo plano, às sequências argumentativas.

A tendência à utilização do relato, no que se refere ao tipo de discurso, é previsível, uma vez que este gênero revela marcas do mundo atual, ou seja, do contexto físico de produção. Normalmente, como se comprova na construção do MDG, e já exemplificado anteriormente, inicia-se por um lead narrativo (primeiro parágrafo ou, às vezes, na forma de uma gravata, subtítulo, box), aproximando-se, dessa forma, do gênero notícia, diferenciando-se desta, porém, pelo fato de a reportagem aprofundarse na análise do tema, apoiada em dados, fatos, fontes, discursos de autoridade, que lhe conferem maior fundamentação.

É interessante notarmos, porém, que alguns suportes optam por produzir reportagens mais breves. Muitas vezes, isso acaba por deixar ainda mais tênue a linha divisória entre os gêneros notícia e reportagem.

Ainda sobre a estrutura da reportagem, destacamos que, cada vez mais, há influência das inovações quanto à diagramação, formas de distribuição dos textos nas páginas. Comumente, este gênero textual se caracteriza por certa hibridização, ao se valer de outros gêneros como a inserção de tabelas, colunas explicativas, entrevistas, infográficos, entre outros. Embora sejam utilizados como recursos que colaboram na progressão temática em questão, apresentam características próprias do gênero original. Isso nos 
leva a concluir que a reportagem, ao se valer dessa estratégia, busca ampliar o conhecimento do interlocutor específico, fazendo com que produza inferências, determinando um posicionamento crítico, em função da abrangência com que os dados são relatados.

Quanto às formas de intitular e/ou legendar as reportagens, em muitos textos há recorrência de uma linguagem de caráter mais conotativo, ambíguo, quando não irônico, humorado, conforme as pretensões interacionais escolhidas pelo locutor, tendo em vista a expectativa do interlocutor específico em relação ao conteúdo esperado.

Cabe resslatar ainda que o uso de diversas linguagens é um recurso comumente encontrado em muitos gêneros textuais de diversas esferas, permitindo uma apresentação mais concisa.

\subsubsection{Estilo Linguístico}

Como a reportagem pertence à ordem do relatar, apresenta a predominância dos verbos no presente do indicativo e no pretérito perfeito do indicativo (simples). O locutor utiliza mais intensamente, de acordo com sua intenção de promover a continuidade e a progressão temática de uma sequência narrativa, verbos no pretérito perfeito, quando pretende sinalizar o fim de um estado de expectativa, e, verbos no presente do indicativo, para indicar um tempo que pressupõe estabilidade. Essas escolhas justificam-se conforme a intencionalidade do locutor em relação aos efeitos que deseja causar no interlocutor. Para Koch:

A recorrência de tempo verbal tem função coesiva, indicando ao leitor/ouvinte que se trata de uma seqüência de comentário ou de relato, de perspectiva retrospectiva ou zero, ou ainda, de primeiro ou segundo plano, no relato (KOCH, 2008, p. 58).

Outro aspecto que detectamos, diz respeito, praticamente, à ausência da utilização de pronomes de $1^{\mathrm{a}}$ ou de $2^{\mathrm{a}}$ pessoa. Quando isto aparece nas reportagens, estão inseridos nos discursos diretos, depoimentos, utilizados como estratégia argumentativa (discurso de autoridade). Ao optar por isso, entendemos que o locutor pretende marcar uma certa impessoalidade ao texto. Além disso, a utilização frequente de discursos diretos na manifestação das muitas vozes que constam no gênero reportagem fazem com que ele se constitua como um texto polifônico.
Segundo Bezerra,

A polifonia se define pela convivência $e$ pela interação, em um mesmo espaço, (...) de uma multiplicidade de vozes $e$ consciências independentes, (...) todas representantes de um determinado universo $e$ marcadas pelas peculiaridades desse universo (...) o que caracteriza a polifonia é a posição do autor como regente de coro de vozes que participam do processo dialógico (BEZERRA, 2005, p.194).

Constatamos, também, em diversas reportagens, o uso de figuras de linguagem, de certas expressões com valor conotativo, irônico, o que demonstra uma intencionalidade por parte do repórter em causar um efeito de descontração, de forma que o leitor se sinta instigado a continuar a leitura. Ainda, em alguns textos, há referências explícitas ao interlocutor ("você"), o que pode ser interpretado como um discurso pretensamente interativo, no sentido de buscar, por meio de uma "aproximação" entre locutor/interlocutor, certa adesão ao tema relatado.

Durante a construção do MDG, verificamos a utilização intensa de expressões que revelavam a posição do locutor em relação ao que se dizia, expressões as quais são denominadas, pela Análise do Discurso, de modalizadores. As expressões mas e ainda classificam-se,às vezes, como modalizadores ao se mostrarem como uma tentativa de induzir o leitor, no sentido de determinar o posicionamento deste. Estas expressões exercem, dessa forma, função argumentativa, isto é, orientam os enunciados em que figuram para determinadas conclusões. Classificam-se, assim, como mais do que simples elementos coesivos.

Além disso, o uso de paráfrases, cadeia de sinônimos, hiperônimos, associação semântica entre as palavras, caracterizam-se como recursos utilizados com a finalidade de manutenção temática, progressão desta, ou até mesmo como forma de modalização, ao promover a retomada constante das mesmas ideias.

Já a função das conjunções, preposições, advérbios, pronomes, articulando a coesão sequencial e referencial nas reportagens, se mostra a partir da sua utilização em períodos normalmente breves, de forma a facilitar a compreensão imediata do conteúdo. Destacamos, além de diversos outros conectivos, o uso recorrente da conjunção aditiva "e" e do pronome relativo "que". O efeito disso se 
mostra na construção de frases bem elaboradas, mas que primam pelo tom de simplicidade, coloquialidade, de acordo com as intenções do locutor e com a esfera de circulação da revista.

A preferência por parágrafos relativamente curtos, mostra-se como uma tendência à exigência dos interlocutores por textos mais concisos, simples, dado o curto espaço de tempo que uma grande parcela destina à leitura de reportagem impressa. Com efeito, o que observamos é uma tendência adotada por alguns suportes por privilegiar/disponibilizar reportagens, muitas vezes, com caráter mais breve. Isso causa, consequentemente, uma aproximação entre as fronteiras da notícia e da reportagem.

A opção por parágrafos relativamente curtos na grande maioria dos textos analisados, assim como a preferência por frases mais simples, períodos não muito complexos, mostra-se como uma forma de manter a atenção do interlocutor.

Sobre recursos de coesão sequencial, que diz respeito aos procedimentos linguísticos por meio dos quais se estabelecem, entre segmentos do texto, diversos tipos de relações semânticas e/ou pragmáticas, à medida que faz o texto progredir, podemos constatar recorrência, dentre outras expressões, ao uso de conjunções aditivas, utilizadas no sentido de somar argumentos/ideias/fatos a favor de determinada conclusão. Observamos, em alguns casos, recorrência ao termo também, por exemplo: "Também não foram observados grandes prejuízos às articulações daqueles que corriam." Sua utilização se mostra muito além do que mero recurso que dá sequência ao que é dito. Este e outros recursos coesivos se apresentam em alguns textos com função argumentativa, isto é, orientam os enunciados em função de determinada conclusão. São chamados modalizadores ou operadores argumentativos.

Frequentemente recorre-se à tentativa de se chamar a atenção para a necessidade de mobilizar o conhecimento de mundo do interlocutor para vincular referências. Isso se constata quando observamos a utilização de frames, dêiticos em diversas reportagens, o que nos leva a refletir sobre a insuficiência do conhecimento linguístico na compreensão do sentido global dos textos.

\section{Considerações acerca da construção de SD, com base na construção prévia do MDG}

Sendo a reportagem um dos principais gêneros jornalísticos, é interessante observar a grande variação deste gênero. Ao selecionar o corpus para a análise por meio do MDG, a fim de obter conhecimentos aprofundados acerca das marcas composicionais e linguísticas do gênero reportagem impressa, deparamo-nos com diversas problemáticas, as quais vão desde a diversidade de formas, influências dos suportes na sua constituição, até a grande variedade de formatos presentes nesta esfera. Definições presentes em alguns dos principais manuais de redação e estilo jornalístico não dão conta sequer das especificidades deste gênero.

Assim, após selecionadas as reportagens impressas, de revistas diversas, direcionadas a diferentes interlocutores, e após análise minuciosa através do MDG, partiu-se para a construção de uma SD. Cabe ressaltar, então, que houve, neste trabalho, tanto a preocupação com os estudos de questões teóricas, na tentativa de esclarecer o conceito de tal gênero (através da análise do MDG produzido), quanto, ao mesmo tempo, uma busca por encontrar meios que deem conta de sua transposição didática adequada.

Isto posto, a construção da Sequência didática, seguindo a adaptação de Costa-Hübes (apud AMOP 2007) e Costa-Hübes (2008), foi implementada em sala de aula, o $4^{\circ}$ ano Técnico em Administração do Colégio Estadual Mário de Andrade, Ensino Médio e Profissionalizante, em Francisco Beltrão, PR.

Durante a seleção e estudo das reportagens, evitamos a escolha centrada por temáticas, optando por referenciar melhor o contexto sócio-histórico de produção, as marcas do gênero, a função social deste em atividades que o configuravam, o meio em que circulam. Isto foi fundamental para que evitar a utilização do texto meramente como pretexto.

Assim, visando trazer aportes para o trabalho com a textualidade em sala de aula, em especial para a questão da transposição didática dos conhecimentos científicos referentes aos gêneros de texto, verificamos, durante seu desenvolvimento e posterior análise, a coerência da proposta de trabalho pautada na Sequência Didática. Tal estratégia se mostrou adequada, uma vez que as atividades desenvolvidas, tendo em vista tanto a construção prévia do $\mathrm{MDG}$, quando da $\mathrm{SD}$, proporcionaram uma maior reflexão sobre o uso efetivo da língua materna. Isto mostra que as especificidades de cada gênero podem (e devem) ser incorporadas às atividades de sala de aula.

Segue abaixo, uma das reportagens produzidas por alunos, após desenvolvimento da 
Figura 05: Imagem de reportagem produzida ao final da aplicação da SD

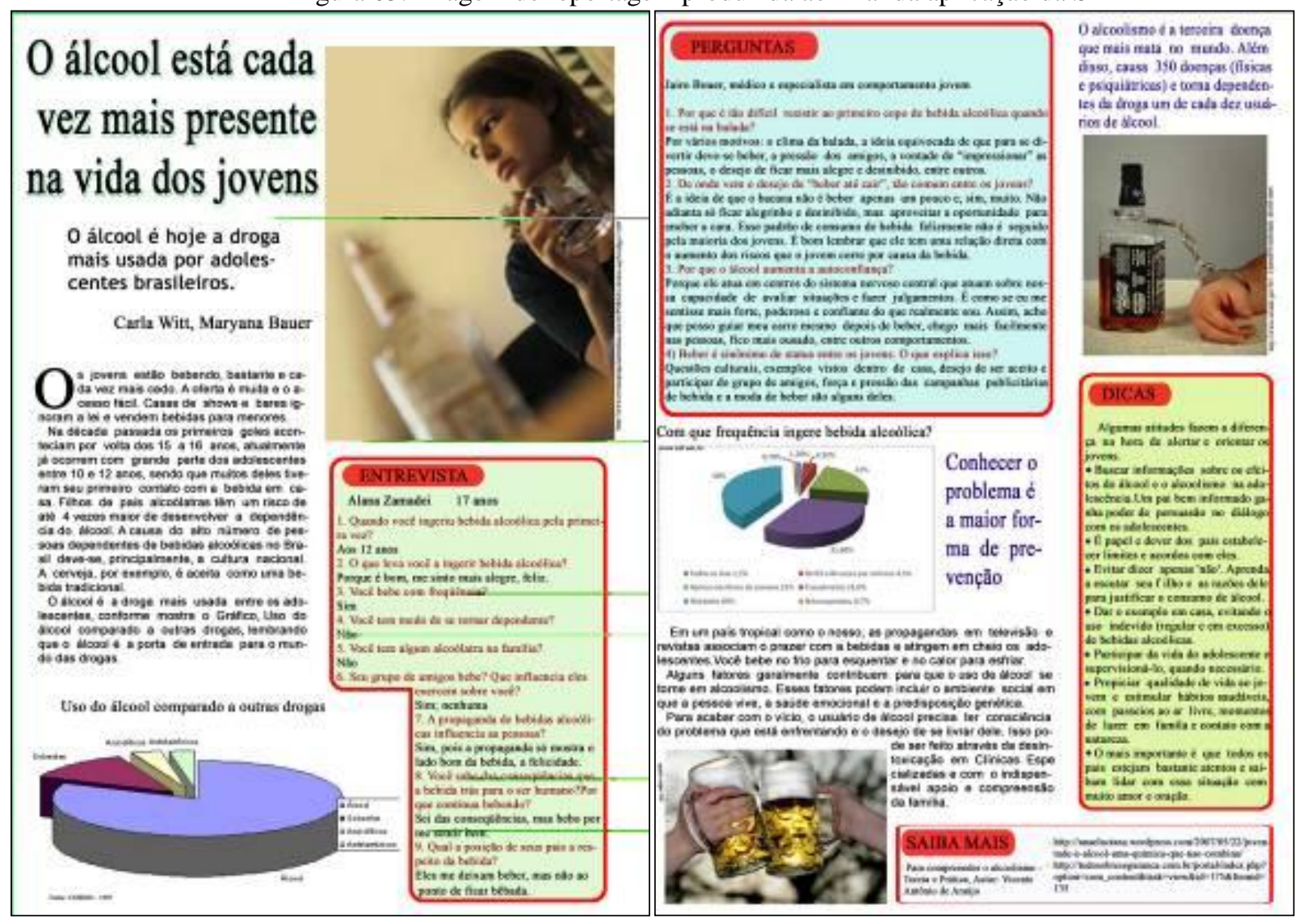

As produções finais demonstraram, em sua maioria, progressão no que se refere aos conteúdos trabalhados durante a SD. As reportagens apresentaram, comparando-se as produções iniciais e as finais, significativo avanço quanto aos conhecimentos acerca do gênero em questão. Tanto o uso das marcas composicionais, quanto linguísticas da reportagem impressa foram verificadas nas produções dos alunos, como por exemplo: hibridismo com outros gêneros; utilização de boxes, estrutura peculiar; linguagem e temática que consideram o interlocutor previamente definidos (jovens); meio de circulação dos textos, dentre outros aspectos, anteriormente citados neste artigo.

O domínio de recursos tecnológicos por parte dos envolvidos neste processo também colaborou para que as reportagens apresentassem uma aproximação maior com os textos analisados, no que diz respeito, especialmente às suas marcas composicionais. Vale lembrar que a escola propiciou abertura para que pudéssemos utilizar o Laboratório de Informática, assim como programas para a diagramação das reportagens.

\section{Considerações finais}

Os pressupostos teóricos levantados sobre os propósitos comunicativos neste trabalho nos levou a observar um aspecto decisivo de sua dimensão discursiva: a ideia de que o conhecimento da dimensão linguística não é suficiente para compreender a totalidade da constituição de um enunciado.

Compreendemos, assim, que a consideração do conjunto de características discursivas de um gênero, neste caso da reportagem, antes mesmo da apreciação do texto propriamente dito e de seu conteúdo, deve constar entre os encaminhamentos iniciais de leitura, uma vez que indica parâmetros de avaliação mais ampla do texto quanto: à forma de abordagem do tema; às relações com outros enunciados; à quantidade e qualidade das informações; ao estilo selecionado pelo locutor; à recorrência ao uso de recursos verbais e nãoverbais. 
Entendemos, também, que o encaminhamento metodológico adequado em relação ao trabalho em sala de aula com os gêneros textuais, neste caso, delimitado pela reportagem, pressupõe, de antemão, a defesa de um conceito de leitura que parta do mais amplo - o âmbito discursivo das produções de textos, conhecimento dos elementos que constituem as situações de produção e circulação do gênero - para o mais específico - seus elementos composicionais, escolhas discursivas, recursos específicos. Dessa forma, entendemos que o texto se constitui sempre como um evento interativo, sendo sempre algo processual.

Nesse sentido, observamos que a consulta a MDG sobre os textos a serem trabalhados (disponíveis em materiais teóricos, fontes diversas), e/ou a prévia elaboração destes, mostra-se como um caminho não somente viável, mas também imprescindível no que se refere às propostas de encaminhamento dos conteúdos básicos de Língua Portuguesa, os gêneros textuais, em sala de aula. Os resultados da implementação da SD nos demonstraram que o estudo dos gêneros (através de MDGs) e a construção conjunta de SDs contribuem para a formação, em princípio do próprio professor, transformando sua prática docente.

Assim, a elaboração de MDG, como pressuposto para posterior construção e/ou trabalho com a metodológica da $S D$, ao estabelecer como ponto essencial o trabalho com o gênero textual, parece ser uma estratégia que pode guiar a intervenção do professor em sala de aula. Tal encaminhamento privilegia diferentes vias de acesso à escrita, diversificação dos gêneros trabalhados, regulada por agrupamentos destes. Pressupõe um trabalho que permite desenvolver as capacidades dos alunos de forma diversa, fazendo com que reflita sobre sua relação com o mundo, considerando situações de uso da textualidade.

\section{Notas}

1 Este texto contempla reflexões realizadas durante nossa participação no Programa de Desenvolvimento Educacional do Paraná (PDE), como professora de educação básica.

\section{Referências}

AMOP, Associação dos Municípios do Oeste do
Paraná. Sequência didática: uma proposta de ensino de Língua Portuguesa para as séries iniciais. [Organizadoras: Carmem Terezinha Baumgärtner; Terezinha da Conceição Costa-Hübes]. Cascavel: Assoeste, 2007a. Caderno 2.

ANTUNES, Irandé. Muito além da gramática: por um ensino de línguas sem pedras no caminho. São Paulo, Parábola Editorial, 2007.

. Avaliação da Produção Textual no Ensino Médio. In: Português no Ensino Médio e formação do Professor. Orgs. Bunzen, Clécio; Mendonça, Márcia. 3. ed. São Paulo: Parábola Editorial, junho, 2009.

BAKHTIN, Mikhail. Estética da Criação Verbal. 4. ed. São Paulo: Martins Fontes, 2003.

Marxismo e filosofia da linguagem. 9. ed. São Paulo: Hucitec, 1999.

BALTAR, Marcos. Competência discursiva $e$ gêneros textuais: uma experiência com o jornal de sala de aula. Caxias do Sul, RS: Educs, 2004.

BRASIL. Parâmetros Curriculares Nacionais: Terceiro e quarto ciclos do Ensino Fundamental: Língua Portuguesa. Brasília: MEC/SEF, 1998.

BEZERRA, Paulo. Polifonia. In: BRAIT, Beth. Bakhtin: conceitos-chave. 2.ed. São Paulo: Contexto, 2005.

BRONCKART, Jean-Paul. Atividade de linguagem, textos e discursos: por um interacionismo sóciodiscursivo. São Paulo: Educ, 2003.

COSTA-HÜBES, T. da C. O processo de formação continuada dos professores do Oeste do Paraná: um resgate histórico-reflexivo da formação em língua portuguesa. Londrina, PR: UEL, 2008 (Tese de doutorado em Estudos da Linguagem).

CRISTÓVÃO, Vera Lúcia Lopes. Modelo Didático de Gênero como instrumento de formação de professores. In: Meurer, José Luiz; Motta-Roth, Désirée (orgs). Gêneros Textuais e práticas discursivas - Subsídios para o ensino da linguagem. Bauru, São Paulo: EDUSC, 2002.

DIONISIO, Ângela Paiva. Gêneros multimodais $e$ multiletramento. In: BRITO, Karim Siebeneicher; 
GAYDECZKA, Beatriz; KARWOSKI, Acir Mario (orgs). Gêneros textuais: reflexões e ensino. Palmas e União da Vitória, PR: Kayagangue, 2005.

DOLZ, Joaquim; NOVERRAZ, Michele; SCHNEUWLY, Bernard. Sequências didáticas para o oral e a escrita: apresentação de um procedimento. . In: SCHNEUWLY, Bernard; DOLZ, Joaquim. e colaboradores. Gêneros orais e escritos na escola. [Tradução e organização: Roxane Rojo e Glaís Sales Cordeiro]. Campinas-SP: Mercado de Letras, 2004.

DOLZ, Joaquim; SCHNEUWLY, Bernard. Gêneros e progressão em expressão oral e escrita elementos para reflexões sobre uma experiência suíça (francófona). . In: SCHNEUWLY, Bernard.; DOLZ, Joaquim. e colaboradores. Gêneros orais $e$ escritos na escola. [Tradução e organização: Roxane Rojo e Glaís Sales Cordeiro]. Campinas-SP: Mercado de Letras, 2004.

GAYDECZKA, Beatriz. A multimodalidade na reportagem impressa. In. Estudos Linguísticos XXXVI(3), setembro-dezembro, 2007. p. 108-115.

$\mathrm{KOCH}$, Ingedore Grunfeld Villaça. A coesão textual. 21. ed. São Paulo, Contexto, 2008.

LAGE, N. A reportagem: teoria e técnica de entrevista e pesquisa jornalística. 2. ed. Rio de Janeiro; São Paulo: Record, 2002.

MACHADO, Anna Rachel; CRISTÓVÃO, Vera Lúcia Lopes. A Construção de Modelos Didáticos de Gêneros: aportes e questionamentos para o ensino de gêneros. Revista Linguagem em (Dis)curso - LemD - Tubarão, v.6, n.3, p. 547-573, set/dez. 2006.

MACHADO, Irene. Gêneros Discursivos. In: BRAIT, Beth. Bakhtin: conceitos-chave. $2^{\mathrm{a}} \mathrm{Ed}$.
São Paulo: Contexto, 2005.

MARCUSCHI, Luiz Antônio. Gêneros textuais: configuração, dinamicidade e circulação. In.: KARWOSKI, Acir Mário. GAYDECZKA, Beatriz; BRITO, Karim Siebeneicher. Gêneros Textuais: Reflexão e ensino. 2. ed. Rio de Janeiro: Lucerna, 2006.

Gêneros textuais: definição $e$ funcionalidade. In: DIONÍSIO, A. P.; MACHADO, A. R.; BEZERRA, M. A. (Org.). Gêneros textuais e ensino.5. ed, Rio de Janeiro: Lucerna. 2007.

Produção Textual, Análise de Gêneros e Compreensão. São Paulo: Parábola Editorial, 2008.

PARANÁ. Secretaria de Estado da Educação. Diretrizes Curriculares da Educação Básica do Paraná. Curitiba: SEED, 2008.

SCHNEUWLY, Bernard; DOLZ, Joaquim. Os gêneros escolares - das práticas de linguagem aos objetos de ensino. In: SCHNEUWLY, Bernard.; DOLZ, Joaquim. e colaboradores. Gêneros orais $e$ escritos na escola. [Tradução e organização: Roxane Rojo e Glaís Sales Cordeiro]. Campinas-SP: Mercado de Letras, 2004.

SWIDERSKI, Rosiane Moreira da Silva; COSTAHÜBES, Terezinha da Conceição. Pesquisa-ação voltada a práticas de leitura: uma proposta de trabalho com gêneros textuais sob a metodologia da sequência didática. In: Anais da XI Jornada de Estudos Linguísticos e Literários. 2008, Marechal Cândido Rondon, 2008.

Abordagem sociointeracionista \& sequência didática: relato de uma experiência. Línguas \& Letras, vol. 10, n.18, $1^{\circ}$ sem. 2009.

VYGOSTSKY, L. S. Pensamento e Linguagem. 2 ed. São Paulo: Martins Fontes, 1989.

\section{Sobre as autoras:}

Rosangela Oro Brocardo: Aluna do Programa de Pós-Graduação Stricto Sensu em Letras, nível de mestrado, da Universidade Estadual do Oeste do Paraná (UNIOESTE), Cascavel, Paraná.

Terezinha da Conceição Costa-Hubes: Profa. Dra. do Programa de Pós-Graduação Stricto Sensu em Letras, nível de Mestrado e Doutorado, e do Curso de Letras Universidade Estadual do Oeste do Paraná (UNIOESTE), Cascavel, Paraná. 
Artigo recebido em novembro de 2013

Artigo aprovado em fevereiro de 2014

Horizontes, v. 32, n. 2, p. 07-20, jan./jun.2014 